\title{
EVOLUTION OF THE TRADITIONAL TURKISH HOUSE
}

\author{
TAMARA KELLY \\ Abu Dhabi University, UAE
}

\begin{abstract}
Cities or its urban fabric arose over many centuries but during the evolution period, architecture lacked its identity and deform premises erected. Architecture progresses according to many factors and among those influences are intangibles as political drive, inspirations from other civilizations, religious guidance. Whereas physical sways such as climate or availability of materials and skilled labours are behind other great architecture formation. Despite all those influences cities nowadays are similar and buildings are identical regardless of their location on the map. Turkish houses changed during various eras to meet the needs of different generations yet maintained robust characteristics and responsiveness. Hayat house is the traditional residential premise and a significant element in Turkish architecture, it is the core of this article. This paper is an attempt to help students and researchers to learn lessons from our ancestors who managed to advance the components of their house and yet created iconic innovative architecture. Furthermore the paper will examine the impact of diverse forces in shaping the distinct character of Turkish houses. The methodology of this paper is based on a literature review of various references and a theoretical analysis of several case studies in Turkey.
\end{abstract}

Keywords: Hayat house, Sofa house, Ottoman architecture, vernacular architecture.

\section{INTRODUCTION}

Houses in Anatolia diverse in materials and layout according to various entities including their location in the mainland, climate, and cultural influences. For instance, a flat roof is a choice for hot regions in Eastern and south Anatolia, sloped roof optimal in northern, western Anatolia and Balkans or black sea plateau. In southern Anatolia, main building materials are stone or mud-brick walls reinforced by wooden beam over a stone foundation. Whereas in northern plateau stone are dominant and houses vary in sizes from small to great palaces. Even with the differences in materials, Ottoman houses share a similar core layout and aspects in many areas. Anatolian Turkmans erected the basic element of a Turkish house in eastern Anatolia, the house layout suits the agricultural environments of Turkmans but in later stages, the house components developed to meet other cultural and religious considerations. Despite the similarity in houses layouts and components between Turkish houses and neighbouring countries, the ottomans created a distinct typology of houses on no occasion that exists anywhere. For instance, Hayat house appears related to many houses in Mesopotamia and Syria but innovated into a unique ottoman style. The following section discusses the fundamental features of Turkish houses and illustrates the advancement of its elements to reach various configurations. Furthermore, many case studies are examined in central and southern districts showing to what extent the character of Hayat house was altered to meet diverse considerations and requirements.

\section{HAYAT OR SOFA HOUSE}

\subsection{First phase, lack of privacy}

Hayat house represents the core and foundation of various Turkish houses styles, the word Hayat is Turkish means Life, and Sofa is a word refers to a common central area veranda or an open gallery. The Hayat house establishes by Turcoman and most Turkmen were nomads migrated from Central Asia or Western China. Turkmen settled in the Anatolian basin in 
around the 11th century and turned into Islam they lived on harvest, breeding and weaves. Hayat house main components are the Ewan (Evan) leading into two-room on its sides and open gallery fronting the Ewan but in later stages, the gallery developed into several modes (Fig. 1). The ground floor raised partially to create a half basement that can be used to suit the rural life such as stable, warehouse or service area. Halil Agha house in Mudanya (Bursa) 1640 reflects Hayat house with a wooden colonnade on the two-tier galleries and the front facade comprises several openings while the side are blinds without any views. The notion of moving between spaces in Hayat house through the exposed or open area is normal for Turcoman since they originally used to live in tenets overlooking their belonging. This approach still exists in houses located in Balkans and many Anatolian regions. As the nomads settled and no longer migrates between lands they applied their custom into new houses where the tents turned to rooms and as a result, the Hayat house initiated. The outline of this house was developed by Turcoman and it is appropriate for their way of living by farming and cattle herders. The open galleries of the house provide a great connection with the surrounding site and overlooking or engagement with farming activities. And this is crucial for ranchers, therefore moving through open spaces between the house components is reasonable for the Turk tribe the occupants of Hayat house.

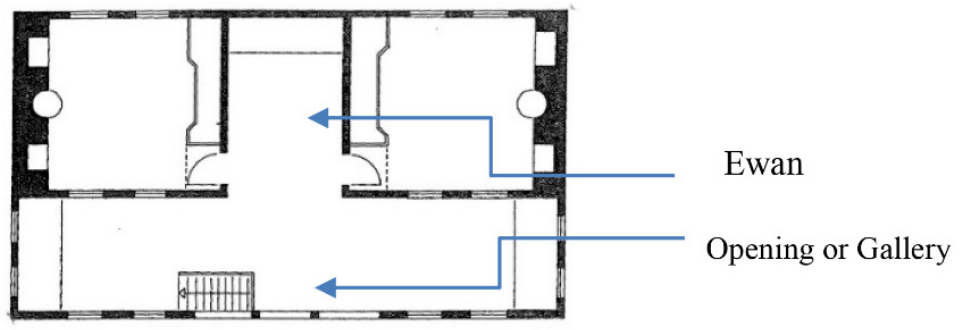

Figure 1: Halil Agah house in Bursa, typical Hayat layout.

But the layout of Hayat house resulted in lacking privacy of women consequently, Hayat house in Islamic norms is unfitting with the privacy concern and the open gallery was undesirable.

\subsection{Stage two, multiple occupations and segregation between male and female sections}

In Islam, the house components must conserve the privacy of women and it is crucial to provide an introverted lifestyle away from the overlooking of outside world, this led to the transformation of the open gallery into an inner courtyard garden creating a semi-closed or semi-open arrangements. Furthermore, new notion elaborated and segregated sections created or allocated for a male and female, this was common in palaces and the houses of the wealthier owner. Likewise, the house of the middle-class family consists of spaces with multi occupations during the day and night. Karel in his book imagine the Turkish house state that the finest room in the house in terms of best lighting, finest motif or furniture and location is dedicated to male entertainment with guests during the day while in the night the room dedicated into the family.

The idea of two separated sections dedicated to males and females commonly found during the 18th and 19th centuries as Muslim, Turkish believe that houses are for family and belong to women in particular since men normally out during the day time. Women in the 
agricultural community engaged heavily with outdoor activities whereas in urban environments spending most of the time at home hence privacy is a key factor in urban residential premises. Consequently, many measures articulate this notion including high walls, concealed opening, lattice or stain glazed windows, introverted plan, an ultimate separation between male and female sections. The guest room and other spaces on the first floor are projected over the street allowing the occupants to overlook any events outside without being seen. Murat house in Bursa is a sample of minor changes to Hayat house to address privacy, therefore all rooms are open towards the gallery Hayat, and side walls extend to the roof reflects the continuity of blind opening on side blank walls a feature of 18 th and 19th centuries (Fig. 2).

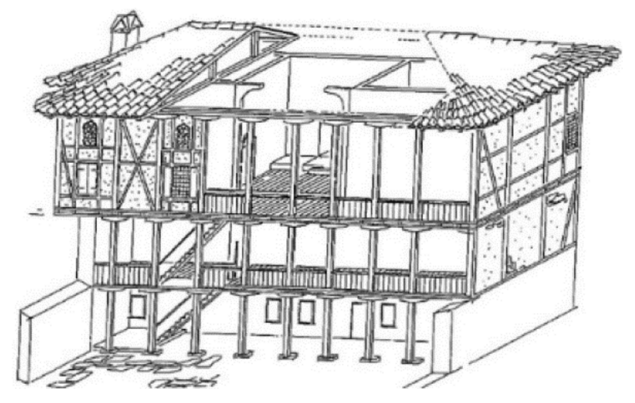

Figure 2: Murat house, blind side without opening.

\subsection{U shape Hayat house and the crucified layout}

The shape of Hayat house progressed further over the years and this can be witnessed in Beyoglu house situated in Manisa (Kula village). The house is a typical model of Hayat all the rooms open into the gallery (Fig. 3). The first floor projected over the lower floor and two rooms or only the gallery extend further with wooden colonnades.

The additive expanded areas were a great new element creating three-dimensional effect and characterized Hayat house. A similar approach was in Cakiraga konab house in Izmir (Birgi village), the house was built at the end of 18th century but substantially rooted in the antiquity reflecting cultural relations with early nomadic. The plan of Cakiraga Konab house is $U$ Shape extended towards the court but yet influenced by the original shape of Hayat layout which consists of two-room flanked around the Evan (Fig. 4). In Cakiraga house two Evan inserted at the end of the gallery and leading into new featured additive rooms forming $U$ outline and facing the garden. The house is extending further inside the court by projected arear erected from the gallery. This outspread space creates newly shaded areas overlooking the garden for socializing, family gathering and provided interaction platform with the external but private scenery. These new components including: projected zone, multiple Evans with the rooms attached into the gallery regarded as a great feature of Turkish houses.

The open Hayat house was transformed in Cakirage case study (Fig. 5) into a semi-open or semi-closed house and this notion will be evolved in later centuries. "The Cakirage Konab in Birgir represents a stage in the development of Hayat ev at which the rural character of the house remained unimpaired and Hayat displayed its most highly developed characteristics" (Ottoman Architecture, p. 478). Nonetheless, soon and in 18th century, the great influence of European culture is commenced on Turkish housed, this resulted in the transformation Hayat house plan from leaner synchronizing into crucifix shape. 


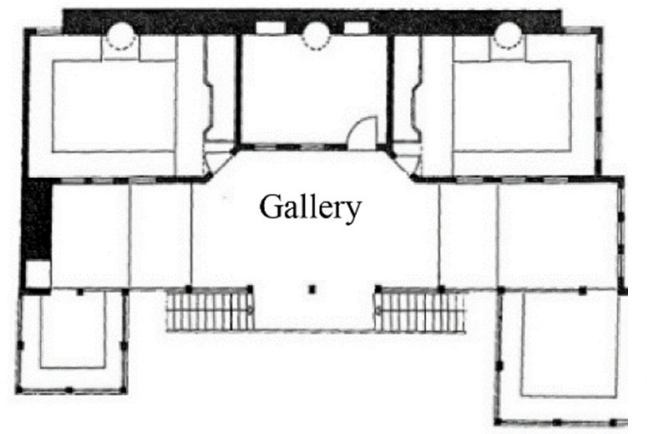

Figure 3: Beyoglu house, u shape.

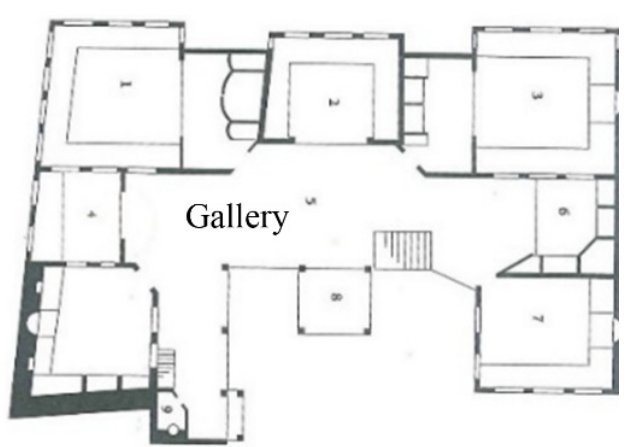

Figure 4: Cakiraga Konab.

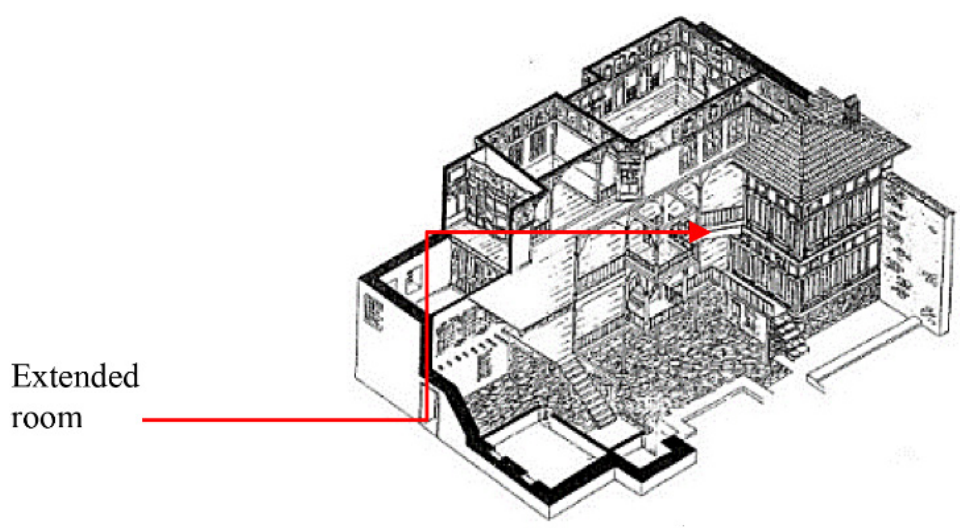

Figure 5: U shape Hayat house, semi open.

This plan based on centralizations or twin access is common in dense urban fabric where the sizes of garden or courtyard minimized or even diminished. According to Dougan, the influence of western architecture was evident in Sipahi Omar house in Izmir (Fig. 6). He believed that the house looks like a church with the crucified opening middle part and fourcornered rooms with great symmetry and axial arrangement "A second reason was the European influences on the house design. Features such as an axial arrangements, symmetry and central halls plan" (Ottoman Architecture, p. 483).

In fact the house is a transformation of Hayat house but as mirrored version around horizontal axes without the opening gallery, which is usually exposed into the surrounding field, however, the four Evans are altered and converted into enclosed spaces. The cornered rooms are projected further and the four Evans appears as crucified spaces inside a square.

In densely populated cities in Central Anatolia or Balkan regions and Istanbul, the Early mentioned centralized house plan was altered and converted into a central sofa extend along the entire length of the house with clustered rooms on each side of the sofa. Furthermore enclosed shared areas are located at the end of the rectangle sofa but with windows allowing connection with the external environment. Although In Istanbul and after world war two massive destructions effected the city centre and vast areas of Istanbul were damaged but this 


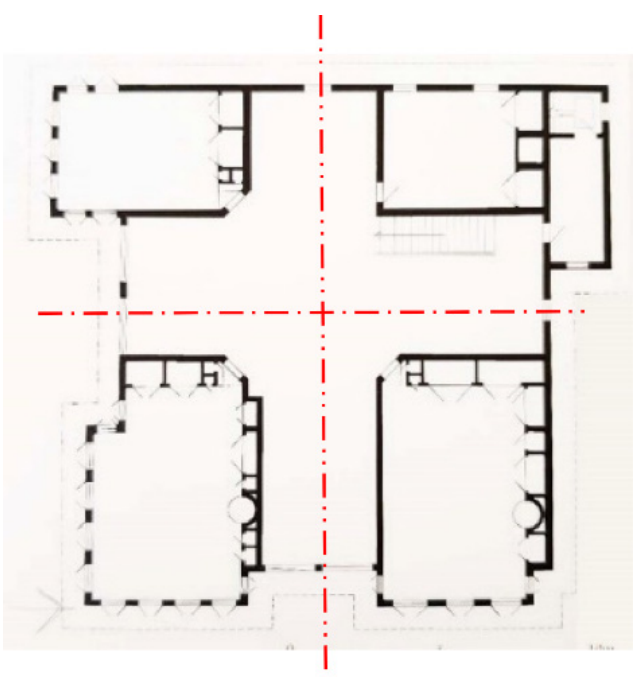

Figure 6: Sipahi house, crucified plan.

house according to many Turkish authors is widely spread in Istanbul and early stated districts. At the end of 19th century new luxurious waterfront houses emerged in Istanbul, it consists of Hayat house layout but clustered around multiple horizontal or vertical axis. Koceoglu palace built-in 18th represents such an approach where the components of Hayat house mirrored around vertical Axis furthermore new elements were added such as the columns in the middle of the main sofa, segregation between male and female is obvious and minor corridors connect these two configurations.

In Koceoglu palace, the distant lower cluster is the female section consisting of multiple private or socializing rooms with the baths (hammam). And follows a centralized arrangement whereas the top units are allocated for male nearer to the entrance welcoming the male visitor (Fig. 7). The plan of Koceoglu palace developed further in Yasinci palace erected at the end of the 18th century.

In Yasinci palace, the edges of the staircases on the sides and main wide Sofa corridors were softened and curved. The palace consist of female section (no male is allowed) and the male section however the arrangement of the sections are mirrored along vertical axis (Fig. 8). The female harmmlek part is clearly distinguished in places from the male salamlik section but in the lower rank of society, this segregation is less obvious nevertheless, the separation approach still exist in the finest living room but the space is alternated between the two genders during the day and night.

Saffet Pasha palace built in Istanbul during the 19th and reflected the notion of seclusion of male and female but the two parts are opposite with the middle service area on the ground floor (Fig. 9). The place follows a cruciform plan, the central outline typology of the palace is a development of Hayat house but paralleled on horizontal Axis. The residence is raised and the entry is through many steps showing the influence of European architecture "in this typology, the basic nucleus of the Hayat ev with central sofa is placed on two sides of the axis and thus converted into a cruciform plan central space, sometimes elliptical, or very rarely circular form" (Ottoman Architecture, p. 486). The layouts of earlier case studies, mostly used in larger residential premises of the wealthier sector of society and merchants who commence commercial trading from home, hence privacy was key factor. 


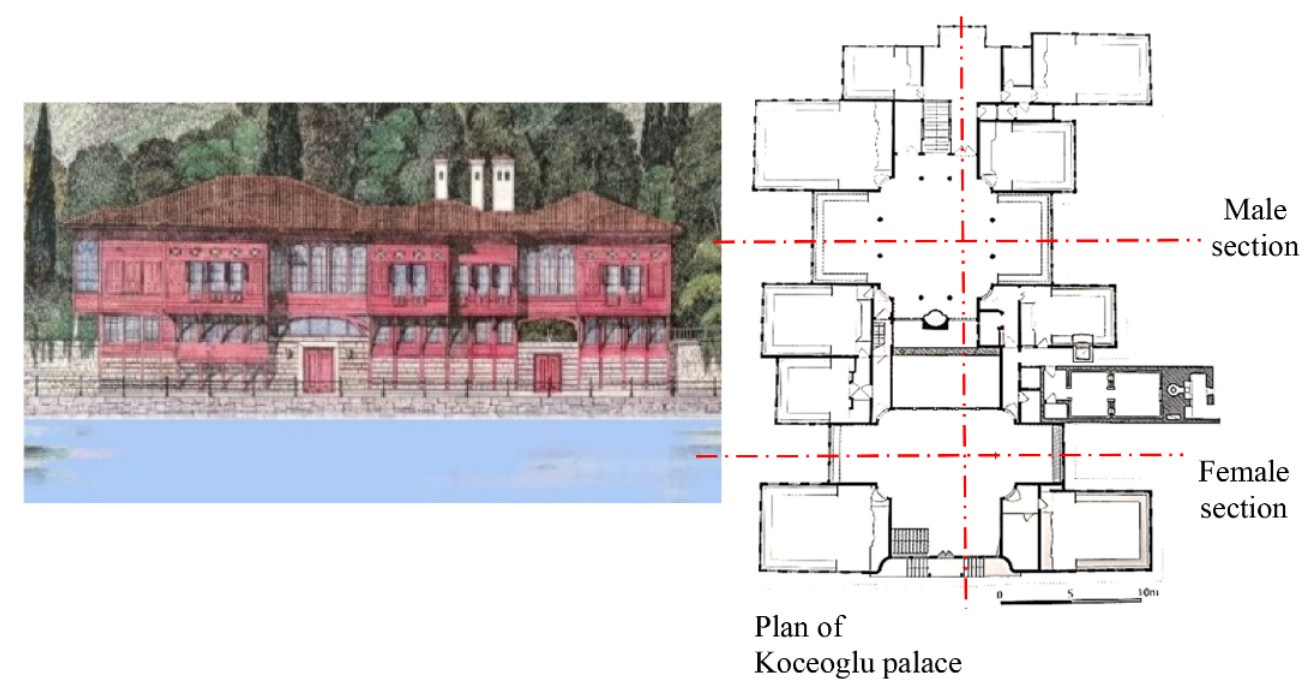

Figure 7: Left is photo Koceoglu palace showing waterside façade reflecting diverse finishing materials.

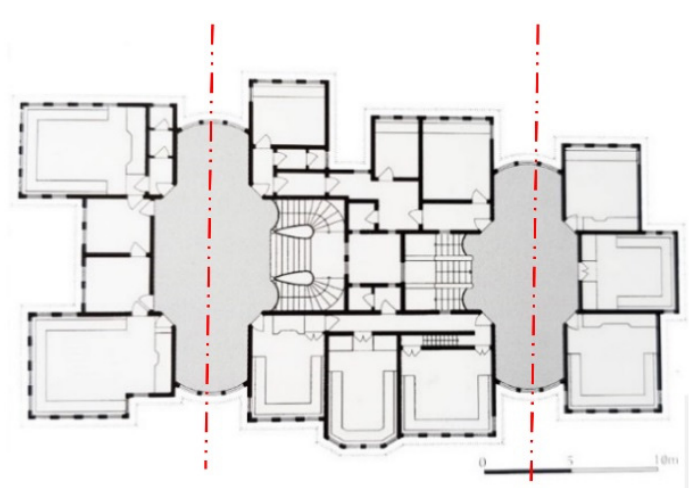

Figure 8: Yasinci palace.

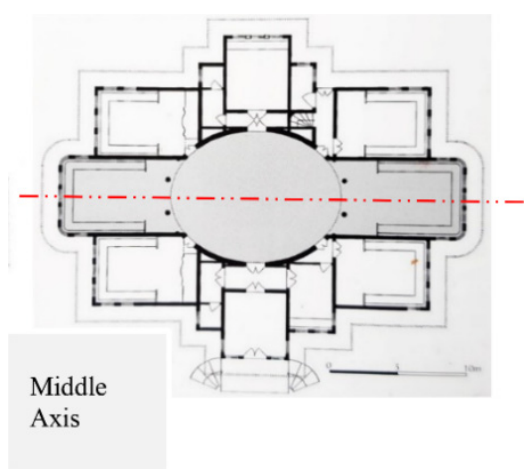

Figure 9: Male opposite female sections, middle sofa Saffet pasha palace.

The Examination of earlier case studies bring to light that diverse arrangements evolved from the original units of Hayat house, the basic components were altered, rearranged or enclosed reflecting religious, social and cultural influences. The numerous units might be dissimilar, inversed and partially reused or arranged around horizontal or vertical Axis Figs 10 and 11 . The sophisticated mixture of units in Hayat house plan is reflected in the structural system, and this was evident in the elevations of Koceoglu palace, or Saffet palaces, as a stone is the foundation materials, the roof is sloped and walls filled by mudbrick between timber frames. 

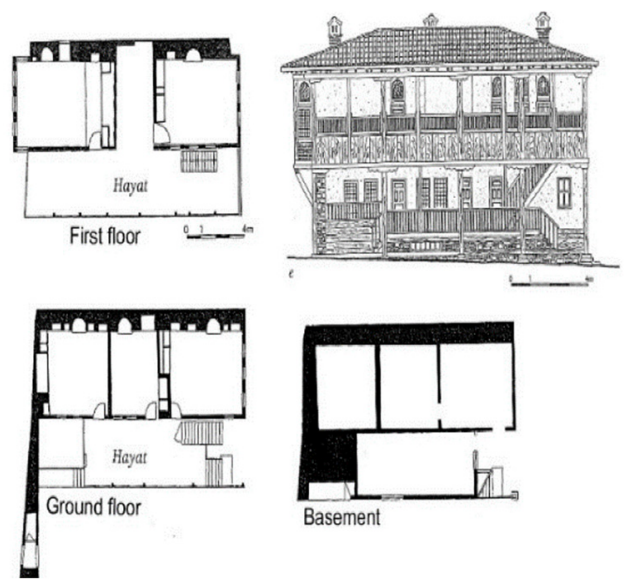

Figure 10: On the left, typical hayat house proposals.

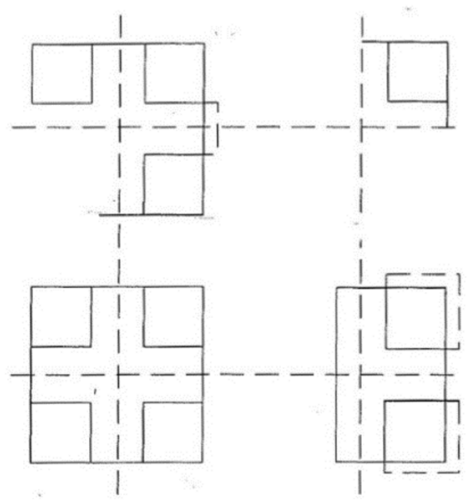

Figure 11: On the right, samples of Hayat house diverse arrangements evolved from the original units of Hayat house, reflecting the influence of many aspects.

\section{THE IMPACT OF NEIGHBOURING SETTING OVER THE HOUSES IN SOUTHERN REGIONS OF TURKEY, DIYARBAKIR CITY}

Turkey surrounded by civilized nations in particular southern provinces, Mesopotamia and Syrian culture cast its shadow over the Turkish architecture. The influence is evident over the house in bordered Turkish regions, for instance, houses in Diyarbakir adopted courtyard layout which is a feature of Syrian traditional houses. Moreover stone and timber are the main materials in Syria and likewise in Diyarbakir and Mardin city. Turkish author Dogan in his publication Turkish Hayat house claimed that Turkish Hayat House is a unique invention of Turcoman but in reality, its components exited before in various neighbouring regions and in particular Mesopotamians. For instance, the Mesopotamian open porticos Tarma house consist of the main features of Hayat house such as; narrower opened colonnade and single Evan with flanked rooms (Fig. 12). In fact, Mesopotamian culture is former than the Turkoman epoch hence the Hayat houses are interrelated with nearby Ancient civilizations and its components inspired by Mesopotamian houses. 


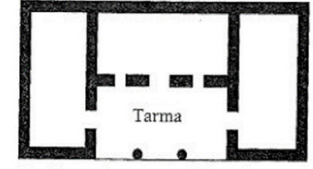

Gallery layout with colonades

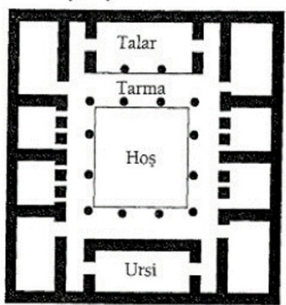

court yard layout

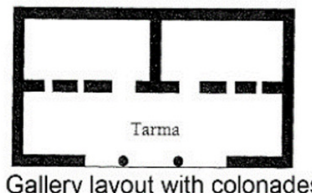

Figure 12: Mesopotamian houses.

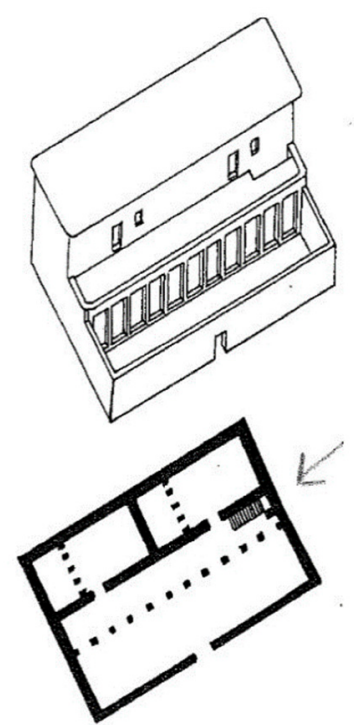

Figure 13: Syrian or Lebanon house.

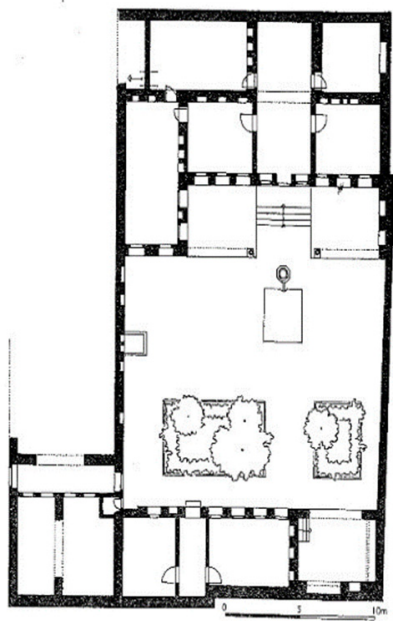

Figure 14: Ocakhouse in Diyarbakir.

Moreover, houses in north Lebanon and Syria accommodates similar arrangement but lacked Ewan (Fig. 13).

However, Dogan underlined minor transformations in Hayat and in particular in the first floor, the gallery is much wider and used as living space instead of a connector or passageway and in later phases, other elements or extensions were added at the ends of the gallery as family gathering areas. In his publication the Ottoman architecture, Dogan believes that the garden courtyard commonly used in Iraq and Syria is replaced by the open gallery were daily activates occur and the portico overlooking the garden. Turkish rural settlements commonly located on sloped terrain and courtyard assemble is challenging hence Hayat house is suitable in villages and agriculture town. Whereas the courtyard and flat roof are common in urban architecture and in hot climate regions located south Turkey.

Diyarbakir is a substantial southern city situated on the banks of the Tigris River closer to Syria and Iraq, the layout of Diyarbakir's house influenced by the neighbouring culture of early mentioned countries. But the Turk added great aspect to the houses, monumentally is key element of the houses in Diyarbakir region reflecting the political and commercial role of the city as informal capital of Kurdish citizens. Houses of this city are prior to Hayat layout but contributed to the initiation of Haya house, however, the layout is still based on the basic design of Hayat plan with a slight alteration of Ewan location. The hot climate resulted in narrow deepening Ewan with a colonnade portico and consequently, the courtyard accommodates fountain to enhance air quality. Privacy and climate are crucial elements in shaping the identity of the house in this city hence windows in all the floors are only inwards looking and the court is enclosed by high walls. Two types of Evan emerge in some houses for winter and summer seasons furthermore a semi-underground basement exit and used during the hot season. The high ceiling is a feature of houses in Diyarbakir and underscored 
the monumental appearance contradicting Hayat house. Fig. 14 shows Ekrem house in Diyarbakir it is a u-shape Hayat house overlooking the garden with other components located beneath the courtyard. Entry to the house is through the opened courtyard and similarly moving between the spaces is within the open-air a feature of Hayat house which is lingered in Diyarbakir residential premises.

\subsection{Mardin and Urfa houses}

Mardin city is located in southern Anatolia and close to the Syrian border, the city is named Cradle of Cultures since it was the centre and a crossroads between different civilizations. Hence the influence of Syrian and Mesopotamian cultures is evident through the choice of materials and house layout. Stone and courtyard are the main features of Syrian houses and likewise, the houses in Mardine adopt inward courtyard arrangement and constructed of stone.

But Houses in Mardin are massive, monumental be like castles and characterized by levelled terraces. The house consists same components of Hayat and Diyarbakir's house inducing covered Evans in the basement and other floors, with numerous terraces overlooking the featured garden (Fig. 15). Mardin houses situated on steep land hence the house is layered following the distinct feature of the terrestrial. The city skyline shows the characteristic houses of Mardin comprising of tiers of courtyards rising above various layers of terraces in great response to the inclined site which resulted in multiple entrances to the house through different floors.

The house of Mardin appears as the foundation of Hayat house with marginal differences for instant the basement in Mardin houses may comprise featured Evan overlooking the water element.
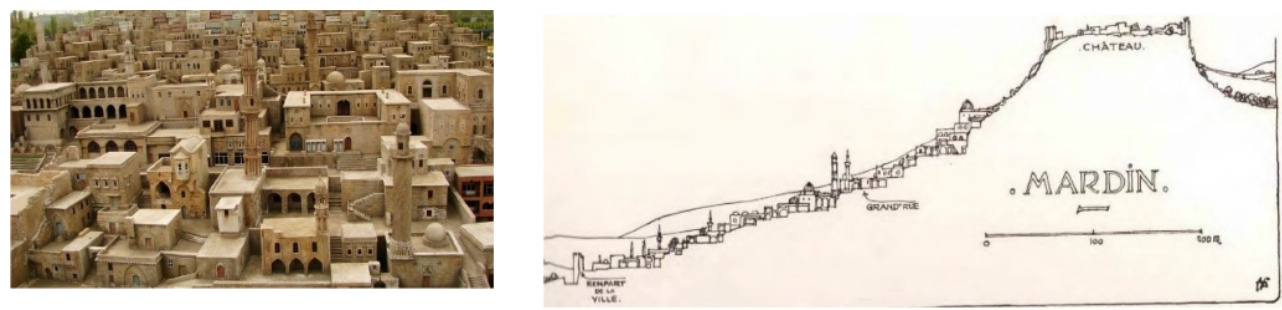

Figure 15: On the left view of Mardin city, houses are massive and monumental. The right is the sections, across urban fabric of Mardin City.

The gallery narrower or replaced by wider terraces Furthermore the court is new elements and all the opening are towards the court (Fig. 16).

\subsection{Urfa}

Urfa is a city of ancient traditions, and great commercial centre during various eras, many civilizations inhabited the city including Roman, Byzantine and Islam moreover, the city is located on the trading paths with southern nations. The houses in this region are distinct and the architectural details were crucial factors in shaping the character of residential premises however courtyard and Evans remain the primary elements of the houses "The Urfa houses 


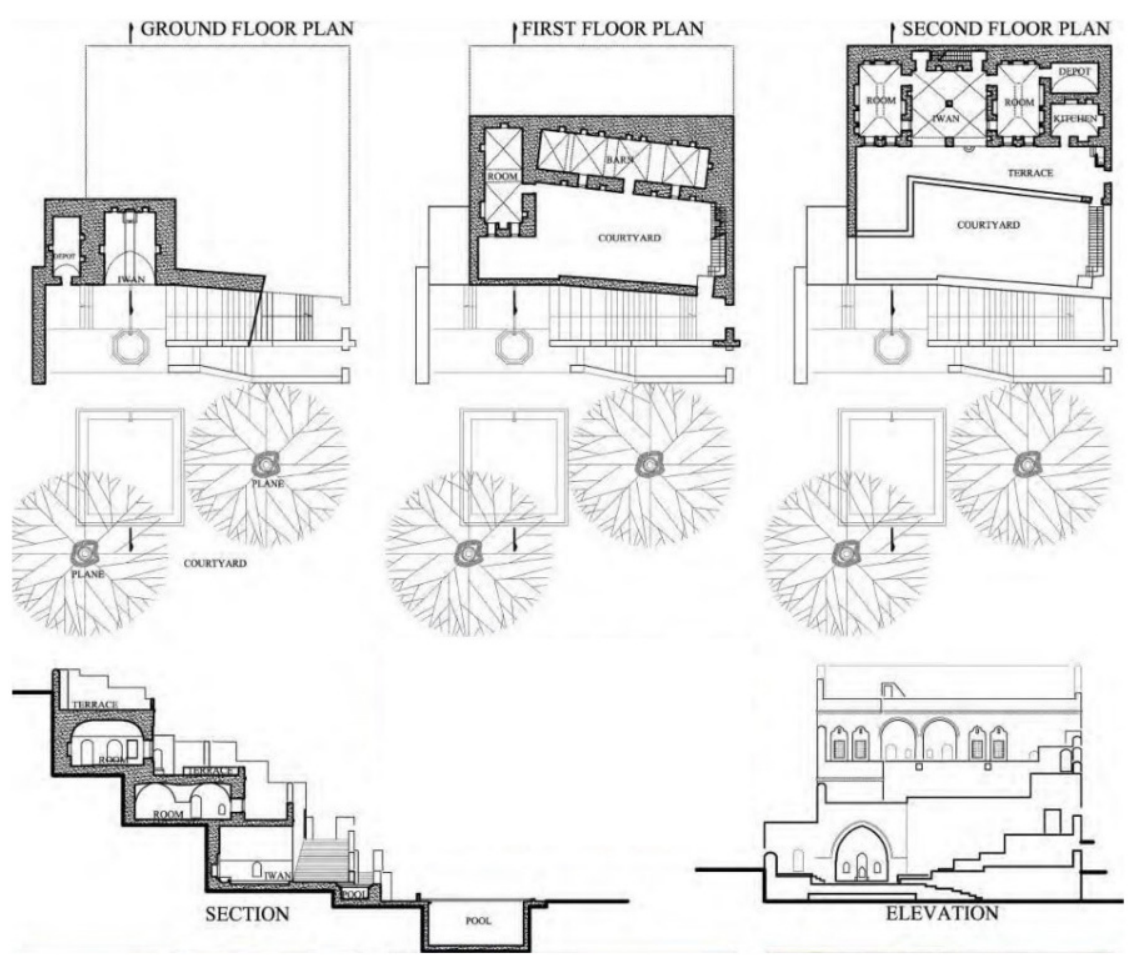

Figure 16: At the top plans of Bahriltor premise. The bottom is the sections showing the distribution of the floors over multiple layers.

display the richest examples of decoration in south-east Anatolia. The heavy consoles with multiple profiles, the cornices composed of rows of small arches, the ornamental tracery in the unglazed head windows of various shapes, the aviaries over the windows, the gezenek balustrades, the windows arches, the medallions adoring the blank walls, the iron railings and balustrades, the door knockers, the woodcarving on the doors in the interior and the wooden shutters are all components of a rich ornamental vocabulary." (Ottoman Architecture, p. 492). The ground floor is above half basement stables with a featured staircase leading into the upper floor and dominating the courtyard. Summer and Winter Evans are additional elements and located in ground level with kitchen open into the courtyard where cooking and food preparation activities take place. In fact, the residue of Hayat house is obvious through Evans and first floor galleries although some house lacks the porticos, yet courtyard is the main connector between the spaces and movements through the open-air likewise Hayat house. The external envelope is concealed and the houses are inwards looking since the climate is hot and dry. Many activities take place in the flat roof during the day including drying the clothes, fruits or herbs whereas socializing or sleeping arises in the evening. Alike the court or Evans serve many uses and living space in summer or winter, but predominantly are employed for food preparation or cooking, seating, playing areas for kids, sleeping, family gathering and wedding or celebrating platform, and circulation between spaces, vegetation, washing and drying clothes, a place for animal and farming, circulation zone, a welcoming entrance and a place for carpet cleaning or weaving (Fig. 17). Hence the size of the courtyard is bigger accommodating family needs, social and 
economic necessities. In wealthy residential premises in Urfa two segregated sections for males and females are common and a barrier as a wall may exist between the haremlik and Salamalik.
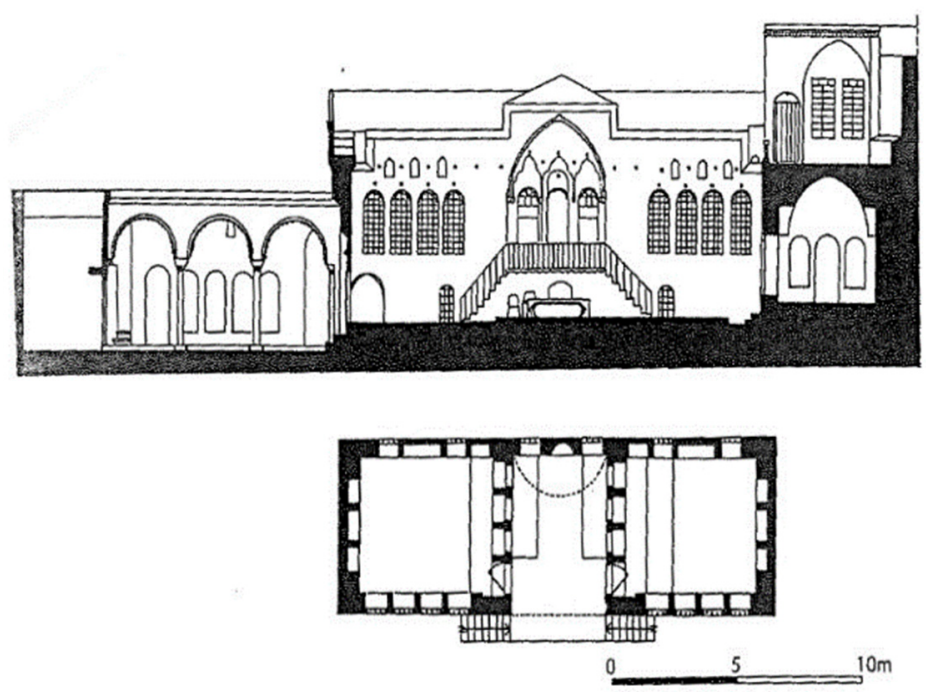

Figure 17: Izgordu house in Urfa.

\subsection{Harran houses}

Evan House is dominated in southeast Anatolia and existed in urban and rural regions but in Harran town, a distinct domed house found consisting of a complex room with various uses. Harran is a plane town located Southeast Urfa, between the two rivers of Euphrates and Tigris. In ancient languages Assyrian and Hittite, the name Harran meant the land between different routes. Harran was established as a merchant centre since its location along the trading path and between the Mediterranean basin and the plains of Tigris River. Harran erected since the third millennium BCE when the area was the cultural and religious centre of settled societies. In the last five hundred years, the city was a temporary settlement of nomad cultures. Therefore and according to many Turkish authors, the existing houses were rebuilt several times during the last centuries. The rudiments of the house are; the courtyard, domed room, and the flexible layout allowing more rooms to be added if needed (Fig. 18). The occupants of the houses are part of the same tribe and live together hence Harran houses are adjacent or nearby resulting in an organic path like the forms of the houses. Inhabitants farm the land and live on stock-breeding, therefore, they live close to the production sources. Consequently, the house consists of many spaces for their animals and storing crops. Each room covered by a square dome and may lead to the adjunct room or the court. Some of the rooms are opened to the courtyard with a small door and in winter, the kitchen is also used as a living room. The hole at the peak of the dome for lighting and as a chimney, while the shape allows for excellent air circulation. The earnings of the building owners, family size and needs govern the number of rooms. As the family members increased, new rooms are added to existing ones or to the court. These domed roofs with opening and according to many historians represent a notion or a practice exited before thousands of years in Northern 
Mesopotamia. Many authors recommend studying the foundation of Harran houses through the Mesopotamian civilizations where excavations showed similar square dome roofing exited during 7th century BC. The influence of Mesopotamian architecture is evident in Harran houses through the domed roof, courtyard, and choice of mud as main construction materials.

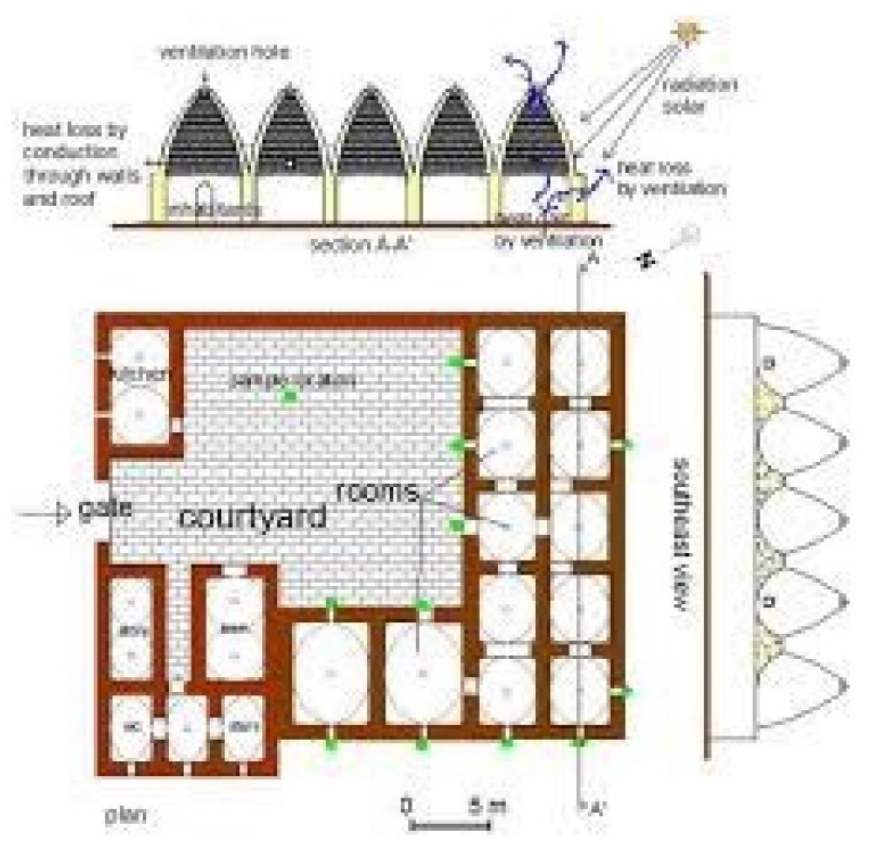

Figure 18: Haran houses.

\section{CONCLUSION}

Houses are key factors of Turkish culture and as important as monumental architecture. Residential premises, in particular, were rooted in agricultural societies and Hayat house erected emphasizing the great connection with surrounding environments. The culture of the Turkmans and according to many Turkish authors can be seen through the great connections with surrounding environments. And the open gallery overlooking the farms in Hayat house represents this conception. In fact the influence of tribe dominating internal details, for instance, the roof of the guest room in many palaces and residential premises accommodates small size dome extended in the middle emitting the tent shape. Moreover, the seating layout is over projection similar to the way adopted by the clan and resulted in creating a divan room known as a male gust room or large assembly room. The head of the tribe normally meets up with the community in his large size tents where law cases heard and the general topic discussed regarding needs and future of the kinfolks. The equivalent approach followed in wealthier residential premises or palaces and Divan space created as a reception room where the Sultan meet with administrators and visitors. The open connecter or gallery with middle Ewan and two rooms on the opposite side underscoring great connection with various activities occurred in the surrounding environment. Furthermore, the open Hayat with Evans regarded as athletic features of Turkish houses and a symbol of historical and cultural 
constituents. During the Islamic reign, the need for privacy surfaces and overshadowed the layout of Hayat house. Privacy considered by various means and the notion development further resulted in deep segregation between male and female sections and in particular in wealthier palaces. In rural areas summer and winter Evan was enclosed and new elements arose including the courtyard with garden or water features. In the 18th and 19th centuries, the sophisticated composition of Hayat cells developed in Istanbul palaces attunes with Islamic considerations yet following western culture. The character of Hayat house reformed under the new social and cultural needs but its components are still the core of various configurations. Nevertheless, and over centuries, Turkish learnt from ancient civilization and managed to address variable needs and advance the elements or notion of Hayat house creating a distinct Turkish style houses.

REFERENCES
[1] Kuban, D., The Turkish Hayat House, Eren, 1995.

[2] Bertram, C., Imagining the Turkish House: Collective Visions of Home, University of Texas Press, 2013.

[3] Kuban, D., Ottoman Architecture, Antique Collectors Club Ltd. Publisher, 2010

[4] Aabidin, M.Z., The Architecture of Ottoman Mosques, Dar Qabess House Publisher, 2005.

[5] Fazio, M., Moffett, M. \& Lawrence Wodehouse, A World History of Architecture, Laurence King Publisher, 2008.

[6] Nehru, J., Glimpses of World History, Asian Publishing House, 1934.

[7] Freely, J., A History of Ottoman Architecture, WIT Press Publisher, 2011.

[8] Necipoglu, G., The Age of Sinan: Architectural Culture in the Ottoman Empire, Reaction Book Ltd., 2007.

[9] Kuran, A., The Mosque in Early Ottoman Architecture, University of Chicago Press, 1968.

[10] Goodwin, G., A History of Ottoman Architecture, Thames \& Hudson Publisher, 2003. 